\title{
JORNAL DE

\section{Trajetórias de formação e profissionais dos diretores de escolas municipais: respostas declaradas ao questionário contextual da Prova Brasil (2015)}

\author{
Training and professionals trajectories of the municipal schools \\ principals: declared answers to the Prova Brasil (2015) contextual \\ questionnaire
}

\section{Trayectorias de formación y profesionales de los directores de escuelas municipales: respuestas declaradas al cuestionario contextual de la Prueba Brasil (2015)}

\author{
Angela Maria Martins ${ }^{1}$ \\ Cristiane Machado ${ }^{2}$ \\ Maria Helena de Aguiar Bravo
}

Citação: MARTINS, A. M.; MACHADO, C.; BRAVO, M. H. A. Trajetórias de formação e profissionais dos diretores de escolas municipais: respostas declaradas ao questionário contextual da Prova Brasil (2015). Jornal de Políticas Educacionais. V. 12, n. 13. Julho de 2018.

http://10.5380/jpe.v12i0.58910

\section{Resumo}

Este artigo apresenta resultados de investigação maior inserida no campo das políticas públicas que examinam características de municípios brasileiros no que se refere à gestão de redes de ensino e/ou que focalizam dinâmicas vigentes em unidades escolares. 0 estudo processou, inicialmente, 111 itens do questionário contextual de diretores de escolas municipais, respondidos na Prova Brasil em 2015, utilizando-se do software IBM SPSS Statistics - 20. Contudo, constatou-se a necessidade de reorganizar o instrumento, considerando 59 itens que respondessem a três dimensões de análise: trajetórias de

\footnotetext{
${ }^{1}$ Doutora em Educação (UNICAMP). Pesquisadora sênior da Fundação Carlos Chagas. Professora do Programa de Mestrado em Educação/Unicid. E-mail: ange.martins@uol.com.br ${ }^{2}$ Doutora em Educação (USP). Professora da Faculdade de Educação da Unicamp. E-mail: cristiane13machado@yahoo.com.br

${ }^{3}$ Doutoranda da Faculdade de Educação da USP. Assistente de pesquisa da Fundação Carlos Chagas. Email: maria.bravo@usp.br
} 
formação e profissional; acesso ao cargo/função; práticas de gestão declaradas por diretores; condicionantes do funcionamento das unidades em redes escolares municipais. Este artigo explora apenas a primeira dimensão que se refere às formas de acesso/ingresso à função/cargo; dados pessoais (sexo, idade, raça); formação inicial e continuada; remuneração; experiência profissional.

Palavras-chaves: Perfil de diretores municipais; Questionário contextual; Trajetórias de formação; Acesso à função.

\begin{abstract}
This article presents results of major research in public policies field that examine the characteristics of Brazilian municipalities in relation to the educational system administration and/or that focus on current dynamics in schools. The study initially processed 111 items from the contextual questionnaire of municipal school principals, answered in Prova Brasil in 2015, using the IBM SPSS Statistics - 20 software. However, it was verified the need to reorganize the instrument, considering 69 items that respond to three dimensions of analysis: training and professional trajectories; access to the position/function; management practices declared by principals; conditioning factors of the school' functioning in municipal education system. This article explores only the first dimension that refers to the forms of access/entry to the principal position; personal data (sex, age, race); initial and continuing training; salary; professional experience.
\end{abstract}

Keywords: School Principals profile; Contextual questionnaire; Training trajectories; Access to the position.

\title{
$R$ esumen
}

Este artículo presenta resultados de investigación mayor insertada en el campo de las políticas públicas que examinan características de municipios brasileños en lo que se refiere a la gestión de redes de enseñanza y/o que focalizan dinámicas vigentes en unidades escolares. El estudio procesó, inicialmente, 111 ítems del cuestionario contextual de directores de escuelas municipales, respondidos en la Prueba Brasil en 2015, utilizando el software IBM SPSS Statistics - 20. Sin embargo, se constató la necesidad de reorganizar el instrumento, considerando 59 ítems que respondieran a tres dimensiones de análisis: trayectorias de formación y profesional; acceso al cargo/función; prácticas de gestión declaradas por directores; en el caso de las empresas de servicios públicos. Este artículo explora sólo la primera dimensión que se refiere a las formas de acceso/ingreso a la función/cargo; datos personales (sexo, edad, raza); formación inicial y continuada; remuneración; experiencia profesional.

Palabras claves: Perfil de directores municipales; Cuestionario contextual; Trayectorias de formación; Acceso a la función.

\section{Introdução}

Este artigo apresenta resultados de um dos aspectos de estudoinserido no campo das políticas públicas, que examinam características e potencialidades de municípios brasileiros no que se refere à gestão de redes de ensino e/ou que focalizam dinâmicas vigentes em unidades escolares, sob diferentes perspectivas. Estes entes federados, desde a Constituição de 1988, assumiram maior autonomia e se tornaram responsáveis pela cobertura de bens e serviços públicos, com diferenciações em sua oferta, decorrentes de suas possibilidades fiscais, políticas e administrativas. No campo da educação a responsabilidade pela oferta da educação básica recai sobre as municipalidades, particularmente na Educação Infantil e no Ensino Fundamental, etapas que preponderantemente vêm sendo atendidas nessa esfera.

A pesquisa original focalizou unidades escolares de municípios brasileiros e caracterizou cenários de gestão vigentes em escolas dessas redes, com base nas 
respostas declaradas pelos diretores municipais ao questionário contextual da Prova Brasil de 2015.

Quanto ao tema "gestão escolar", conta-se com estudos da área, inclusive, com sistematização da produção do campo, por meio de estados da arte e/ou estados do conhecimento (MAIA, 2008; MARTINS, 2011; PEREIRA, 2005; SOUZA, 2006) que indicam a diversidade de concepções e abordagens metodológicas em torno do tema, explorado por meio de distintos objetos.

Dentre outras temáticas, destaquem-se: práticas de diretores e sua articulação com o corpo docente para a elaboração do projeto político-pedagógico; seu papel na construção de processos de autonomia pedagógica, financeira e administrativa de escolas; constituição e funcionamento de conselhos escolares; modalidades de provimento do cargo de direção, no contexto da heterogeneidade de sistemas e redes de ensino; importância do diretor como o profissional que propicia um clima organizacional favorável para as relações de trabalho no cotidiano escolar; relevância de suas funções na eficácia da utilização dos recursos financeiros e de materiais didáticopedagógicos; o clima escolar, as relações de convivência, a cultura juvenil, as situações de indisciplina, os conflitos e a violência em escolas públicas (MARTINS; MACHADO, 2016; GALVÃO et al., 2010); a participação da comunidade escolar por meio de gestão compartilhada (BRITO; SILVERES, 2015; VELOSO; CRAVEIRO; RUFINO, 2012); as questões que incidem na formação do pedagogo e suas práticas profissionais (BARBOSA; ABDIAN, 2013); a gestão democrática e compartilhada em contraposição ao viés gerencialista que tem marcado as políticas educacionais (LIMA; PRADO; SHIMAMOTO, 2011; CABRAL NETO; CASTRO, 2011); a disputa de poder no âmbito da gestão escolar (SOUZA, 2012).

Gonçalves, Martins (2017) ao analisarem o papel do diretor escolar na organização e funcionamento do Conselho de Escolas, discutem que as interações entre os atores escolares no trabalho cotidiano fazem emergir diferentes relações de poder, exigindo de diretores ações mais assertivas para a construção de um clima organizacional favorável para convivências baseadas na colaboração. Os padrões de comportamento, as normas veladas, os rituais, as formas de pensamento e os valores que a comunidade escolar partilha para interagir e se organizar, constituem eixos estruturantes para o processo de aprendizagem institucional das escolas, na medida em que há partilha entre quem chega e quem já faz parte do grupo há algum tempo. 
As concepções e crenças comuns de um grupo profissional se constituem em respostas por eles aprendidas nas práticas pedagógicas e de gestão, em contextos de desafios frente aos problemas externos ou internos. Assim, por mais que exista uma estrutura de funcionamento e um conjunto de regras comuns para escolas de uma mesma rede de ensino, cada profissional interpreta e coloca em prática de acordo com suas possibilidades e trajetórias pessoais e profissionais (MARTINS, 2008).

De modo geral, suas funções se reúnem em torno dos seguintes aspectos: administrar as finanças da escola; saber aplicar verbas e prestar contas aos órgãos colegiados da escola, aos pais/responsáveis sobre o uso dos recursos financeiros; cuidar da parte de infra estrutura - limpeza, manutenção, segurança, organização dos espaços comuns e das salas de aula; articular a participação de professores na elaboração e implementação do projeto político-pedagógico (PPP); instituir espaço/clima que proporcione bom relacionamento entre todos os segmentos que compõem a comunidade escolar (professores, funcionários, alunos, famílias e responsáveis); acompanhar o processo de ensino e de aprendizagem, com vistas a garantir uma educação de qualidade aos alunos; divulgar e discutir resultados das avaliações educacionais de sua escola; ter clareza das características socioeconômicas dos alunos e do contexto onde vivem; conhecer a legislação educacional emanada da União, do estado e do município para discutir com o corpo docente possibilidades e limites de sua implementação na unidade escolar; assegurar processos participativos na organização e funcionamento dos órgãos colegiados escolares; promover a abertura da escola para alunos, famílias, responsáveis e a comunidade do contexto onde se localiza a unidade escolar.

Nesse contexto, um dos aspectos relevantes no campo dos debates e estudos sobre gestão escolar, se refere ao perfil de diretores, tendo em vista a heterogeneidade de redes e sistemas de ensino no Brasil. Neste artigo, focalizamos trajetórias de formação e profissionais dos diretores, assim como o acesso/ingresso à função/cargo em redes municipais, com base nas respostas declaradas no questionário contextual da Prova Brasil (2015).

\section{Procedimentos metodológicos}


Os Questionários Contextuais da Aneb e Anresc (Prova Brasil) servem como instrumentos de coleta de informações sobre aspectos da vida escolar, do nível socioeconômico, do capital social e cultural dos alunos são apresentados em formato de múltipla escolha, aplicados aos alunos, professores e diretores antes da realização do teste e devem ser recolhidos ao final da prova. Na mesma ocasião, é preenchido pelos aplicadores dos testes um formulário sobre a escola que levanta dados sobre as condições de infraestrutura, segurança e recursos pedagógicos disponíveis.

A utilização do questionário contextual da Prova Brasil como fonte de pesquisa tem sido apontada por pesquisadores da área de educação como relevante, uma vez que levanta informações de diversas dimensões e situações da gestão escolar, em âmbito nacional. Entretanto, limites e problemas em sua estrutura e nos constructos das questões também têm sido assinalados como fatores que devem ser vistos com cuidado pelo órgão gestor, o Instituto Nacional de Estudos e Pesquisas Anísio Teixeira (Inep), conforme se discute adiante.

Analisando as características dos questionários contextuais do Sistema de Avaliação da Educação Básica (Saeb) 2001, Franco et al. (2003), embora apontem limitações do instrumento - como a necessidade de refinamento e clareza da linguagem usada e o aprimoramento das medidas de motivação e autoestima - destacam que este é adequado para pesquisas e investigações sobre possíveis efeitos produzidos pela escola no desempenho dos alunos. Segundo os autores (2003, p. 66), a adequada mensuração dos efeitos produzidos pela escola deve levar em conta medidas cognitivas, medidas acerca do aluno e medidas acerca da própria escola, dimensões contempladas pelos instrumentos do Saeb.

Com base nos dados do Saeb/2001, Soares (2011) investigou fatores escolares que podem ser associados ao desempenho dos alunos da $8^{\underline{a}}$ série do ensino fundamental em matemática e concluiu, dentre outras afirmações, que os fatores escolares podem explicar $12,3 \%$ da variância dos dados, explica o autor que:

Esse valor mostra, por um lado, que mesmo após o controle das diferenças socioeconômicas entre o alunado das diversas escolas, a maior parte da variação da proficiência deve ainda ser atribuída a variações intrínsecas aos alunos. No entanto, o valor remanescente, compatível com os trabalhos internacionais na área, é suficientemente grande para reconhecermos que existe variação entre as escolas de maneira que a escola frequentada faz diferença na vida do aluno. Em outras palavras, é possível melhorar o desempenho dos alunos através da ação sobre as estruturas escolares (p. 195). 
Os debates indicam limites decorrentes da configuração dos questionários contextuais e, concomitantemente, a potencialidade dos usos dos dados gerados com a aplicação destes instrumentos como fonte de informação, para subsidiar análises e reflexões sobre as políticas educacionais e a gestão escolar.

Com essa compreensão, a investigação original processou, inicialmente, 111 itens do questionário contextual de diretores de escolas municipais, respondidos na Prova Brasil em 2015, que tratam de diversos aspectos da gestão escolar, considerados, no estudo, como dados relevantes para responder aos objetivos propostos.

É preciso esclarecer que - assim como constatado em estudos anteriormente citados - foram identificados problemas no que se refere à validade dos constructos das questões que compõem o questionário contextual. Dessa forma, o processamento preliminar do software IBM SPSS Statistics - 20 gerou tabelas de contingência com a frequência das respostas fornecidas pelos diretores aos 111 itens, permitindo uma primeira aproximação das características de perfil desses profissionais, bem como uma compreensão inicial das informações coletadas pelo questionário no que tange à sua forma e conteúdo. Com base nessa primeira apreciação, os conteúdos dos itens do questionário contextual foram reorganizados e levou-se em consideração 59 questões, tendo em vista que muitos desses conteúdos encontram-se dispersas ao longo do instrumento.

Para esclarecer, destacamos os três eixos de análise originados do processo de reorganizaçãodos itens: a) Trajetórias de formação e profissional; acesso ao cargo/função - Reúne os itens do questionário referentes a dados pessoais (idade; sexo); à formação inicial e continuada; à remuneração; à experiência profissional e ao acesso/ingresso no cargo/função (questões reorganizadas - 1 a 25 e inclusão da questão 79); b) Práticas de gestão declaradas pelos diretores - Reúne os itens referentes às práticas declaradas pelos diretores no que tange ao número de reuniões dos conselhos de escola e de classe; elaboração do Projeto Político Pedagógico; participação de famílias e demais membros da comunidade no espaço escolar; oferta de vagas e critérios para a admissão de alunos; alocação de turmas aos professores; iniciativas para lidar com o abandono e a reprovação escolar e ações de reforço à aprendizagem dos alunos; projetos desenvolvidos para o enfrentamento de problemas do cotidiano escolar, especificamente os que incidem nas situações de indisciplina, conflito e violência 
(questões reorganizadas - 29 a 32, 53 e 54); c) Condicionantes do funcionamento das unidades em redes escolares municipais - Reúne os itens tangentes a recursos financeiros, humanos e materiais; abstenção docente e discente; rotatividade docente (questões reorganizadas - 67, 69 a 71 e 73 a 75).

\section{Trajetórias de formação e profissionais dos diretores, assim como o acesso/ingresso à função/cargo em redes municipais.}

As questões de 1 a 25 e a questão 79, apresentadas no Questionário Contextual da PB de 2015 aos diretores, versam sobre os diferentes aspectos relacionados ao perfil do gestor:formas de acesso/ingresso à função/cargo; dados pessoais (sexo, idade, raça); formação inicial e continuada; remuneração; experiência profissional.

Apresentamos a seguir algumas das distribuições de respostas dadas a essas questões, que permitem caracterizar os respondentes do questionário no ano de 2015.

A divisão por sexo apresenta um quadro majoritariamente feminino, com 84,6\% do total de respondentes do EFI e 75,8\% dos respondentes de EFII sendo mulheres. Essa proporção de homens e mulheres pode ser encontrada praticamente em todos os estados, exceto Acre, Amazonas e Amapá, onde a concentração de diretores homens se aproxima de 30\%. A prevalência de mulheres nos cargos de direção das escolas corrobora as análises sobre feminização da carreira docente na educação básica (VIANNA, 2002; 2013), refletindo tendência de feminização do magistério iniciada com a expansão do ensino público primário no final do século XIX. Conforme Vianna (2002, p. 85), "essa característica mantém-se por todo o século XX, estimulada, sobretudo, pelas intensas transformações econômicas, demográficas, sociais, culturais e políticas por que passa o país e que acabam por determinar uma grande participação feminina no mercado de trabalho em geral".

Esta tendência foi observada por Souza (2009) em estudo que analisou o perfil dos diretores com base nos dados do Saeb de 2003. 0 autor identificou que a maioria das direções escolares era ocupada por mulheres, no entanto, elas se encontravam especialmente nas escolas de ensino fundamental e os homens nas escolas de ensino médio. Concluiu o autor que "conforme se avança nos níveis e etapas de ensino, encontram-se proporcionalmente mais homens diretores, o que corresponde ao crescimento também do número de professores homens nas etapas e níveis mais avançados" (SOUZA, 2009 p. 02). 
Com relação à idade, $86,6 \%$ dos diretores de EFI e 86,2\% dos diretores de EFII se concentravam na faixa de 30 a 54 anos, denotando que estes, em geral, já se encontravam no meio de suas carreiras na educação. Este dado foi reafirmado quando se observa o tempo entre a obtenção da maior escolaridade e o ingresso/acesso na função/cargo de diretor, com a concentração de cerca de $40 \%$ das respostas no intervalo entre 8 a 14 anos e aproximadamente 18\% das respostas indicando mais de 15 anos de formação para todo o Ensino Fundamental.

A divisão racial percentual dos diretores municipais brasileiros em 2015 se apresentava da seguinte maneira:

Tabela 1. Distribuição racial dos diretores municipais brasileiros

\begin{tabular}{l|r|r|r|r}
\hline \multirow{2}{*}{ Raça } & \multicolumn{2}{|c|}{ Anos iniciais } & \multicolumn{2}{c}{ Anos Finais } \\
\cline { 2 - 5 } & \multicolumn{1}{c|}{$\mathrm{N}$} & \multicolumn{1}{c}{$\%$} & $\mathrm{~N}$ & \multicolumn{1}{c}{$\%$} \\
\hline Branco(a). & 12927 & 43,7 & 5399 & 39,3 \\
\hline Pardo(a). & 12809 & 43,3 & 6471 & 47,1 \\
\hline Preto(a). & 2692 & 9,1 & 1291 & 9,4 \\
\hline Amarelo(a). & 680 & 2,3 & 330 & 2,4 \\
\hline Indígena. & 207 & 0,7 & 110 & 0,8 \\
\hline Não quero declarar. & 177 & 0,6 & 110 & 0,8 \\
\hline Não sei. & 89 & 0,3 & 27 & 0,2 \\
\hline TOTAL & 29581 & 100 & 13739 & 100 \\
\hline Fonte: Questionário contextual da Prova Brasil de 2015
\end{tabular}

No âmbito da divisão racial por estados da federação observa-se que os estados da Bahia, Santa Catarina e Rio Grande do Sul apresentam números distintos da distribuição geral. Em 2015 os diretores na Bahia eram 14,2\% (691) brancos, 57,2\% (2.775) pardos e 23\% (1.120) pretos; em Santa Catarina 88,6\% (1.633) brancos, 8,4\% (154) pardos e 1,4\% (26) pretos; no Rio Grande do Sul 89,3\% (2.632) brancos, 5,9\% (173) pardos e 3\% (89) pretos.

Deve-se salientar, contudo, que a distribuição racial dos diretores observada aqui tem relações diretas com a persistência de diferenças na distribuição dos grupos raciais pelo país, que apresenta maior concentração de pretos e pardos nas regiões Norte e Nordeste e de brancos nas regiões Sudeste e Sul.

Com relação à dependência administrativa da instituição de Educação Superior, observa-se que os números relativos à formação inicial em universidades públicas estaduais e federais totalizam 37,8\% dos diretores de EFI e 39,8\% de EFII. Contudo, 
salienta-se que a formação inicial realizada em instituição privada apresenta os maiores percentuais, sendo 59,1\% dos diretores de EFI e 57\% dos de EFII. Ainda se ressalta que $33,3 \%$ do total de diretores municipais brasileiros são formados em universidades particulares e chegam àfunção/cargo via indicação.

Esses dados corroboram estudo realizado por Gatti et al. (2009) no que se refere à atratividade da carreira docente, que analisa o perfil de ingressantes no magistério, e ressalta que os estudantes, com seus poucos recursos disponíveis para investimento e acesso aos bens culturais e baixos desempenhos em testes padronizados e exames vestibulares, formam-se em instituições privadas de educação superior. Esse quadro ainda é potencializado devido às condições de oferta de vagas em Ensino Superior, uma vez que as vagas em universidades públicas estão centradas, em geral, nos grandes centros urbanos.

Em relação aos diretores que afirmaram possuir pós-graduação em 2015, a maior parte se concentrava em cursos da modalidade lato sensu, com aproximadamente $74 \%$ do total de diretores afirmando possuir esse tipo de especialização. Para a modalidade stricto sensu, aproximadamente 3\% do total de diretores municipais afirmou possuir mestrado e outros $0,2 \%$ afirmou possuir doutorado. Quando perguntados se participaram de atividades de formação nos últimos dois anos, 83\% dos diretores responderam afirmativamente. Concorreram, certamente, para esse cenário a intensificação da importância e visibilidade da função/cargo de diretor, tanto por força legal como, também, pelas exigências de maiores qualificações profissionais para melhores salários e funções/cargos apresentadas nos planos de carreira do magistério.

As questões sobre salário aparecem em dois formatos, na pergunta 10, sobre salário bruto de diretor (com adicionais), e na pergunta 12 , sobre salário bruto total. Para o primeiro caso, observa-se como tendência uma concentração nas faixas salarias de $\mathrm{R} \$ 3.940,01$ até $\mathrm{R} \$ 5.516,00$ (22,6\% EFI e 22,2\% EFII), de $\mathrm{R} \$ 3.152,01$ até $\mathrm{R} \$$ $3.940,00$ (17,2\% EFI e 16,1\% EFII) e de R\$ 2.758,01 até R\$ 3.152,00 (13,4\% EFI e 13,3\% EFII). Dado esse quadro, os diretores municipais tendem a receber de três a seis salários mínimos brasileiros ${ }^{4}$, o que os classificaria nas classes econômicas D e C, de acordo com a definição de Classes Sociais por faixas de Salário-Mínimo do Instituto Brasileiro de Geografia e Estatística (IBGE).

${ }^{4}$ O valor do Salário Mínimo brasileiro para o ano de 2015 foi definido em R\$ 788,00. 
Dos diretores municipais, $25,1 \%$ dos de EFI e 30,1\% dos de EFII afirmaram exercer outra atividade para complementação de sua renda. Esse quadro, de acordo com os estudos de Oliveira (2004) sobre a precarização do trabalho docente, teria relação com os baixos salários oferecidos, onde os docentes precisariam trabalhar em mais de uma escola e, não raras vezes, mais de 40 horas por semana. Há que se destacar que os diretores, geralmente, possuem salários superiores ao dos docentes e que sua função/cargo, comumente, exige 40 horas semanais de dedicação, razões que poderiam explicar apenas um terço dos diretores exercer outra atividade além da direção de escola 5 .

Esse quadro é reafirmado quando se analisam as informações fornecidas pelos diretores à questão sobre sua carga horária de trabalho semanal. Dos respondentes, $27,1 \%$ dos diretores de EFI e 31,6\% dos de EFII afirmaram trabalhar mais de 40 horas, $66,9 \%$ dos de EFI e 62,9\% dos diretores de EFII afirmaram trabalhar 40 horas, 5,7\% dos de EFI e 5,2\% dos diretores de EFII afirmaram trabalhar de 20 a 39 horas, e 0,3\% dos diretores, tanto para EFI quanto para EFII, afirmaram trabalhar menos de 20 horas.

No questionário apresentado aos diretores, a questão 14, referente às formas de provimento da função/cargo de diretor, traz como alternativas de resposta: "Concurso público apenas; Eleição apenas; Indicação apenas; Processo seletivo apenas; Processo seletivo e Eleição; Processo seletivo e Indicação; ou Outra forma". A presença destas alternativas e de combinações entre elas já indicam, por si só, a coexistência de formas diversas de escolha de diretores que apresentam, intrinsecamente, distintas concepções sobre o papel do gestor e, consequentemente, dos processos de gestão desenvolvidos nas escolas.

Para os dados analisados, observa-se grande quantidade de diretores que chegou à função/cargo por meio de indicação apenas, 56\% dos diretores de EFI e 61,6\% dos diretores de EFII; outros 5,3\% dos diretores de EFI e 5,4\% dos de EFII, acessaram/ingressoua função/cargo por uma combinação entre processo seletivo e indicação. Souza (2006) atenta para o fato de que as indicações para a função/cargo de diretor são, comumente, realizadas pelos administradores dos sistemas de ensino ou

\footnotetext{
5Sobre essa discussão, ver: JACOMINI, M. A.; ALVES, T.; CAMARGO, R. B. Plano Nacional de Educação e Remuneração Docente: desafios para omonitoramento da valorização profissional no contexto da Meta 17. In: 37ạ Reunião Nacional da ANPEd, 2015, Florianópolis. Anais... Florianópolis: UFPR, 2015. http://37reuniao.anped.org.br/wp-content/uploads/2015/02/Trabalho-GT05-4065.pdf
} 
políticos e, apesar de poderem estar relacionadas a outros critérios de seleção, esse processo configuraria uma prática com forte carga política.

Outros 21\% dos diretores municipais de EFI e 17,7\% dos diretores de EFII afirmaram ter acessado/ingressado na função/cargo por meio de eleição apenas, além de 6,7\% de diretores para EFI e 6\% para EF II que o fizeram por meio de combinações entre processo seletivo e eleição. Souza (2009) aponta este procedimento como um mecanismo de provimento das funções/cargos, aparentemente, mais democrático ou mais transparente. Ainda, para o autor, estas duas formas, articuladas ou isoladas, se baseariam em compreensões distintas e, ao mesmo tempo, complementares sobre o papel de diretor, sendo o conhecimento técnico e as funções burocráticas fundamentais na seleção e a representação ou liderança política fundamentais na eleição.

Atenta-se ao fato de que apenas 5,6\% dos diretores de EFI e 4,1\% dos de EFII acessaram/ingressaram na função/cargo por meio de concurso público. Por fim, 2,8\% dos diretores de EFI e 2,6\% dos diretores de EFII afirmaram terem acessado/ingressado na função/cargo por outra forma, sem indicar qual seria esta, o que não permite explorar suas características e vinculação com procedimentos de democratização de acesso/ingresso na função/cargo.

Quando perguntados sobre o tempo de trabalho como professores antes de assumirem as funções/cargos de direção, observa-se que 49,7\% dos diretores de EFI e 49,1\% dos diretores de EF II situam-se na faixa de 6 a 15 anos, denotando estarem no meio de suas carreiras. Outros 34,1\% dos diretores de EFI e 34\% dos diretores de EFII afirmaram ter mais de 16 anos na profissão. Chama atenção que, ainda que de maneira residual, há casos de diretores com menos de dois anos nas funções de docência sendo 1,5\% no EFI e 1,6\% no EFII que afirmaram nunca terem trabalhado como professores, $1 \%$ no EFI e 1,1\% no EFII que afirmaram ter trabalhado menos de um ano como professores e 3,1\% no EFI e 3,3\% no EFII que afirmaram ter trabalhado como professores entre um e dois anos.

Parte desses diretores apresenta um perfil com menos tempo de formação, sendo que 12,2\% têm menos de dois anos de formação e 39\% entre dois e sete anos de formação e 35,5\% exercem a função de diretor há menos de dois anos, sendo que 45,6\% estão na escola em que atuam atualmente também há menos de dois anos. Observa-se que a maior parte deles, $74,3 \%$ do total, chegou ao cargo por meio de indicação, o que 
sugere pouca preocupação dos gestores dos sistemas de ensino ou dos políticos envolvidos com a experiência daqueles que indicam à função/cargo.

Com relação aos anos na função/cargo de diretor, o maior contingente se apresenta entre três e cinco anos (33,3\% EFI e 34,2\% EFII), seguidos de seis a 10 anos (21,2\% EFI e 20,6\% EFII), de um a dois anos (17,6\% EFI e 17,5\% EFII) e menos de um ano (12,9\% EFI e 13,8\% EFII). Quando perguntados sobre o tempo de permanência como diretor na atual escola, o maior contingente se apresenta entre três e cinco anos (35,5\% EFI e 35,8\% EFII), seguidos de um a dois anos (22,8\% EFI e 23,3\% EFII) e menos de um ano (18,6\% EFI e 20,1\% EFII). Esse quadro evidencia que cerca de 30\% do total de diretores de escolas municipais no Brasil tem pouca experiência na função/cargo e está há pouco tempo nas escolas em que trabalham atualmente - menos de dois anos.

Ressalta-se ainda que, mesmo com a definição de Diretrizes Nacionais para a Educação Especial na Educação Básica, que versa, entre outros, sobre a necessidade de assegurar aos alunos com necessidades educacionais especiais currículos, métodos, técnicas, recursos educativos e organização específica para atender às suas necessidades, 94\% dos diretores de EFI e 93,3\% dos diretores de EFII não contam com formação específica nesse campo.

\section{Considerações finais}

A análise do perfil dos diretores apresenta um panorama sobre características dos dirigentes escolares municipais. Em síntese, os profissionais que ocupavam a direção escolar em 2015 eram predominantemente mulheres, com maior concentração nos anos iniciais do ensino fundamental, distribuídos entre pardos (90,5\%) e brancos $(83,1 \%)$. Com relação à faixa etária, eles se encontram no meio para o final de suas carreiras profissionais, obtiveram sua maior escolaridade em instituições de ensino superior privadas e a maior parte possui pós-graduação em cursos da modalidade lato sensu.

Quanto aos salários, destaca-se que os diretores municipais tendem a receber de três a seis salários mínimos brasileiros, o que os classificaria nas classes econômicas D e C (IBGE, 2015). Essa baixa remuneração salarial pode explicar o fato de que aproximadamente um terço dos profissionais exerce outra para complementação de renda. 
0 acesso/ingresso na função/cargo se deu, majoritariamente, por meio de indicação ou de processos combinados com indicação, situação que evidencia a centralização no poder executivo dos processos de condução dos profissionais que irão exercer a direção escolar, o que indica excessivo peso em escolhas que podem ter maiores vínculos político-partidários do que, exatamente, a indicação de profissionais cujo perfil combine competência técnica ao compromisso político com uma educação pública de qualidade.

No que tange ao provimento das funções/cargos de diretor, ainda que não haja no Brasil uma uniformidade na escolha dos dirigentes das escolas públicas nas redes estaduais ou municipais, para alguns autores (PINTO, 1994; PARO, 1995) esse provimento poderia ser uma variável definidora no que se refere ao nível de comprometimento do dirigente com a unidade escolar. Para Souza (2009), as formas de provimento das funções/cargos podem demonstrar, também, a compreensão que a administração do sistema de ensino tem sobre o trabalho a ser desempenhado, pois esta seria uma ação essencialmente política.

Embora não desconsideremos a importância da participação e do poder de escolha das comunidades, elucida-se que a eleição da equipe gestora, por si só, não garante práticas democráticas de gestão, devendo ser acompanhada de outras ações voltadas ao envolvimento da comunidade escolar nas decisões que a afetam, pois chama a atenção o fato de que apenas 5,6\% dos diretores de EFI e 4,1\% dos de EFII acessaram/ingressaram na função/cargo por meio de concurso público.

Contudo, vale destacar também que o acesso/ingresso na função/cargo de diretor por concurso não combinado a outros recursos, pode ser interpretado como uma maior relevância atribuída pela gestão do sistema à formação e às especificidades técnicas da função de dirigente escolar, o que não implica também, em garantia de perfil propício ao exercício de funções desafiadoras no trabalho cotidiano da gestão escolar.

\section{Referências:}

BARBOSA, Andrea Haddad; ABDIAN, Graziela Zambão. Gestão escolar e formação do pedagogo: relações e implicações a partir da análise de projetos político-pedagógicos de universidades públicas. Educação em Revista, Belo Horizonte, v.29, n.04, p. 245-276, dez. 2013

BRITO, Renato de Oliveira; SÍVERES, Luiz. As características da participação da comunidade escolar em um modelo de gestão compartilhada. Sophia, Armenia, Colômbia, v. II, p. 9-20, 2015. 
CABRAL NETO, Antônio; CASTRO, Alda Maria Duarte Araújo. Gestão escolar em instituições de ensino médio: entre a gestão democrática e a gerencial. Educação \& Sociedade, Campinas, v. 32, n. 116, p. 745-770, jul./set. 2011.

FRANCO, Creso; FERNANDES, Cristiano; SOARES, José Francisco; BELTRÃO, Kaizô; BARBOSA, Maria Eugênia; ALVES, Maria Tereza Gonzaga. 0 referencial teórico na construção dos questionários contextuais do Saeb 2001. Estudos em Avaliação Educacional, n. 28, p. 39-74, 2003.

FRANCO, Creso et al. Qualidade e eqüidade em educação: reconsiderando o significado de "fatores intra-escolares".Ensaio: avaliação e políticas públicas em educação, Rio de Janeiro, v. 15, n. 55, p. 277-298, 2007.

GALVÃo, Afonso et al. Violências escolares: implicações para a gestão e o currículo. Ensaio: avaliação e políticas públicas em educação, Rio de Janeiro, v. 18, n. 68, p. 425-442, jul./set. 2010.

GATTI, Bernadete A. et al. Atratividade da carreira docente no Brasil. São Paulo: FCC, 2009. (Relatório final)

GONÇALVES, Adriana R; MARTINS, Angela M. Conselho Escolar: o papel do diretor na participação dos diferentessegmentos em escolas públicas. In: VII Encontro de Políticas Públicas de Educação eFormação de Professores - Políticas Educacionais, Formação e Prática Docente:cenários e experiências. Universidade Cidade de São Paulo. Anais...São Paulo, 2017.

JACOMINI, M. A.; ALVES, T.; CAMARGO, R. B. Plano Nacional de Educação e Remuneração Docente: desafios para o monitoramento da valorização profissional no contexto da Meta 17. In: 37ạ Reunião Nacional da ANPEd, 2015, Florianópolis. Anais... Florianópolis: UFPR, 2015. http://37reuniao.anped.org.br/wp-content/uploads/2015/02/TrabalhoGT05-4065.pdf

LIMA, Antonio Bosco; PRADO, Jeovandir Campos; SHIMAMOTO, Simone Vieira de Melo. Gestão democrática, gestão gerencial e gestão compartilhada: novos nomes velhos rumos. In: SIMPÓSIO BRASILEIRO DE POLÍTICA E ADMINISTRAÇÃO DA EDUCAÇÃO, 25, São Paulo. Anais: PUC-SP, p. 1-13, 2011.

MAIA, Graziela Zambão Abdian. As publicações da ANPAE e a trajetória do conhecimento em administração da educação no Brasil. Revista Brasileira de Política e Administração da Educação, Porto Alegre, v. 24, n. 1, p. 31-50, jan./abr 2008.

MARTINS, Angela Maria. O contexto escolar e a dinâmica de órgãos colegiados: uma contribuição ao debate sobre gestão de escolas. Ensaio. Avaliação e Políticas Públicas em Educação, v.16, p.195 - 206, 2008.

MARTINS, Ângela Maria (Org.). Estado da Arte: gestão, autonomia escolar e órgãos colegiados (2000-2008). Brasília: Líber Livros, 2011.

MARTINS, Angela M.; MACHADO, Cristiane. Gestão escolar, situações de conflito e violência: campo de tensão em escolas públicas. Educar em Revista (Impresso), v.59, p.157 - 173, 2016.

PARO, Vitor Henrique. Por dentro da escola pública. São Paulo: Xamã, 1995.

PEREIRA, Gilson. R. de M.; ANDRADE, Maria da Conceição Lima de. A Construção da Administração da Educação na RBAE (1983-1996). Educação \& Sociedade, Campinas, v. 26, n. 93, 1393-1411, set./dez., 2005. 
PINTO, José Marcelino Rezende. Administração e liberdade: um estudo do conselho de escola à luz da ação comunicativa de Jürgen Habermas. 1994. Tese de Doutorado. Faculdade de Educação da Universidade Estadual de Campinas. 1994.

SOARES, José Francisco. 0 efeito da escola no desempenho cognitivo de seus alunos. In: MELLO E SOUZA, Alberto (Ed.). Dimensões da avaliação educacional. Petrópolis: Vozes, 2011. p. 174-204.

SOUZA. Ângelo Ricardo de. Os caminhos da produção científica sobre a gestão escolar no Brasil. Revista Brasileira de Política e Administração da Educação, Porto Alegre, v. 22, n. 1, p. 13-39, jan/jun.2006.

Explorando e construindo um conceito de gestão escolar democrática.Educação em Revista, vol. 25, n. 3, p. 123-140, dez. 2009.

A natureza política da gestão escolar e as disputas pelo poder na escola.Revista Brasileira de Educação, vol. 17, n. 49, p. 159-174, abr. 2012.

VELOSO, Luísa; CRAVEIRO, Daniela; RUFINO, Isabel. Participação da comunidade educativa na gestão escolar. Educação e Pesquisa, São Paulo, v. 38, n. 04, p. 815-832, out./dez., 2012

VIANNA, Cláudia Pereira. O sexo e o gênero da docência. Cadernos Pagu [online], n.1718, p. 81-103, 2002

. A feminização do magistério na educação básica e os desafios para a prática e a identidade coletiva docente. In: YANNOULAS, Silvia Cristina (org.). Trabalhadoras: Análise da feminização das profissões e ocupações. Brasília, DF: Abaré, p. 159-180, 2013. 


\title{
JORNAL DE POLÍTICAS EducACIONAIS
}

\begin{abstract}
(C)
SOMERIIGHIS RESERVED O Copyright é retido pelo/a autor/a (ou primeiro co-autor) que outorga o direito da primeira publicação ao Jornal de Políticas Educacionais. Mais informação da licença de CreativeCommons encontram-se em http://creativecommons.org/licenses/by-nc-nd/2.5. Qualquer outro uso deve ser aprovado em conjunto pelo/s autor/es e pelo periódico.

JoRnal de Políticas EduCACIONAIS é uma publicação do Núcleo de PolíticasEducacionaisdo Setor de Educação da Universidade Federal do Paraná - NuPE/UFPR, em consórcio com a Linha de Pesquisa em Políticas Educacionais do Programa de Pós-Graduação em Educação - PPGE/UFPR, que aceita colaboração, reservando-se o direito de publicar ou não o material espontaneamente enviado à redação. As colaborações devem ser enviadas ao NuPE/UFPR, conforme orientações contidas nas páginas do periódico na internet: http://revistas.ufpr.br/jpe.
\end{abstract}

\author{
Indexação: \\ BBE - Biblioteca Brasileira de Educação (MEC/INEP) \\ Clase (Base de Datos Bibliográfica de Revistas de Ciencias Sociales y Humanidades) \\ Diadorim - Diretório de Política de Acesso Aberto das Revistas Científicas Brasileiras (IBICT) \\ Google Scholar \\ Index Copernicus \\ Portal de Periódicos (CAPES) \\ SER - Sistema Eletrônico de Revistas da Universidade Federal do Paraná (SER/UFPR) \\ Sumários de Revistas Brasileiras (FUNPEC-RP) \\ DRJI - Directory of Research Journals Indexing
}

(Periódico integralmente disponível apenas em via eletrônica)

Jornal de Políticas Educacionais / Núcleo de Políticas Educacionais da Universidade Federal do Paraná NuPE/UFPR - v.1, n. 1 (1o semestre de 2007) - Curitiba: NuPE/UFPR.

Volume 12, número 13 - Julho de 2018

ISSN 1981-1969

1. Educação - Periódicos. 2. Política Educacional - Periódicos. I. NuPE/UFPR

Comitê Editorial:

Ângelo Ricardo de Souza (UFPR)

Ana Lorena Bruel (UFPR)

Marcos Alexandre Ferraz (UFPR)

Conselho Editorial:

Andréa Barbosa Gouveia (UFPR), Ângela Hidalgo (UNICENTRO), Cesar GernominoTello (Universidad Nacional TresFebrero, Argentina),Gladys Beatriz Barreyro (USP), Juca Gil (UFRGS), Jefferson Mainardes (UEPG), João Ferreira de Oliveira (UFG), Luiz Souza Júnior (UFPB), Marcos Edgard Bassi (UFSC), Regina 
MARTINS, A. M.; MACHADO, C.; BRAVO, M. H. Trajetórias de formação e profissionais dos diretores de escolas municipais: respostas declaradas ao questionário contextual da Prova Brasil (2015)

Maria Michelotto (UFPR), Robert Verhine (UFBA), Rosana Cruz (UFPI), Rubens Barbosa Camargo (USP), Sebastián Donoso Díaz (Universidad de Talca, Chile), Taís Moura Tavares (UFPR), TheresaAdrião (UNICAMP), Vera Peroni (UFRGS).

\author{
Jornal de Políticas Educacionais \\ Universidade Federal do Paraná \\ Setor de Educação \\ Núcleo de Políticas Educacionais - NuPE/UFPR \\ Rua Gal. Carneiro, 460 - 4o andar - Sala 407/C \\ 80.060-150 - Curitiba - PR - Brasil \\ Tel.: 41-3360-5380 \\ jpe@ufpr.br \\ http://revistas.ufpr.br/jpe
}

